\title{
DEVELOPMENT AND VALIDATION OF ANALYTICAL METHOD FOR ASSESSMENT OF CALCIUM DOBESILATE IN VARIED HYDROGEL COMPOSITIONS
}

\author{
ANNA LISIK, EWA PILCH, LAURA SŁOWIAK and WITOLD MUSIAŁ*
}

Wroclaw Medical University, Pharmaceutical Faculty, Department of Physical Chemistry, Borowska 211, 50-556 Wrocław, Poland

\begin{abstract}
Standardized analytical methods for testing pharmaceutical preparations are not readily available in the literature for calcium dobesilate hydrogels. The aim of the study was to develop and validate an analytical method for methylcellulose gel containing calcium dobesilate as an active ingredient. Samples from dissolution experiments were assessed via HPLC with UV-VIS detector. The optimal composition of mobile phase included acetonitrile with water $1: 1$, acidified to $2.5 \mathrm{pH}$ value. The applied column was Standard Purospher Star $18 \mathrm{e}$ $250 \times 4.6(5 \mu \mathrm{m})$, and the maximum wavelength was set at $240 \mathrm{~nm}$, at $25^{\circ} \mathrm{C}$. The total run time of analysis was set at $5 \mathrm{~min}$ and acquired retention time was 2.7 and $3.1 \mathrm{~min}$ for calcium dobesilate depending on the hydrogel formulation. A validity study of the method revealed that all obtained calibration curves showed good linearity $\left(r^{2}>0.9927\right)$. Eight different calcium dobesilate hydrogel formulations were tested. Linearity (100\% level) was found to be $99-101 \%$ for all formulations. Trueness was in the range of $98-102 \%$ on three different spike levels for all eight formulations. Precision results were around $100 \%$ with RSD lower than $1 \%$ in all cases indicating that the method can be used as a validated method. Limit of quantitation (LOQ) was found to be 13.25 ěg/mL for all eight formulations. The method is feasible for evaluation of hydrophilic gels with calcium dobesilate.
\end{abstract}

Keywords: calcium dobesilate, HPLC, validation, hydrogel, methylcellulose

Calcium dobesilate (CD) is a small biologically active molecule, a calcium salt of 2,5-dihydroxybenzenesulfonic acid - Figure 1.

CD has well-defined pharmacological properties. It blocks hyperpermeability of the blood vessels and inhibits platelet aggregation. CD improves blood circulation in the lymphatic vessels, as well as increases the elasticity of red blood cells (1). The synthesis of prostaglandins and thromboxanes, and angiogenesis was inhibited in experimental settings after application of CD (2). Due to the influence on

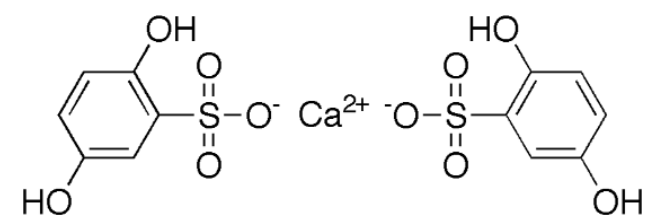

Figure 1. Calcium dobesilate structure the microcirculation $\mathrm{CD}$ is used in venous insufficiency. The study of treatment of diabetic retinopathy demonstrated the antioxidant activity of calcium dobesilate (3). The adverse drug reactions of $\mathrm{CD}$ include gastrointestinal disorders, drug fever and agranulocytosis (4). In former research our team evaluated the $\mathrm{CD}$ transfer via artificial membrane and pork ear skin, from methylcellulose hydrogel for topical formulation with $\mathrm{CD}$, according to the high applicative value of hydrogels as topical drug carriers $(5,6)$. We used simple spectrophotometric evaluation of the released drug, and compared conditions suitable for evaluation of CD release using paddle over extraction cell assembly $(5,6)$.

Hydrogels are three-dimensional polymeric systems with high swelling properties. They are capable of retaining large quantities of water and body fluids in a biological environment (7). In the pharmaceutical industry, they are widely applied as carriers for active pharmaceutical ingredients

\footnotetext{
* Corresponding author: e-mail: witold.musial@umed.wroc.pl
} 
Table 1. The composition of the prepared gels comprising CD and various components.

\begin{tabular}{|c|c|c|c|c|c|c|}
\hline \multirow{2}{*}{ Formulation } & \multicolumn{7}{|c|}{ Composition [\%] } \\
\cline { 2 - 7 } & $\mathrm{CD}$ & $\mathrm{MC}$ & $\mathrm{ET}$ & $\mathrm{LT}$ & $\mathrm{CL}$ & Aq. \\
\hline $\mathrm{A}$ & 2.500 & 1.500 & - & - & - & 96.000 \\
\hline $\mathrm{B}$ & 2.500 & 1.500 & 20.000 & - & - & 76.000 \\
\hline C & 2.500 & 1.500 & 48.000 & - & - & 48.000 \\
\hline D & 2.500 & 1.500 & - & 0.041 & - & 95.599 \\
\hline E & 2.500 & 1.500 & 20.000 & 0.041 & - & 75.959 \\
\hline F & 2.500 & 1.500 & 48.000 & 0.041 & - & 47.959 \\
\hline G & 2.500 & 1.500 & 20.000 & 0.040 & 0.004 & 75.956 \\
\hline H & 2.500 & 1.500 & 48.000 & 0.040 & 0.004 & 47.956 \\
\hline
\end{tabular}

CD - calcium dobesilate (\%LOD: 5.28), MC - methylcellulose, ET - ethanol, LT - lecithin, CL - cholesterol, Aq. - water

(APIs), due to their advantageous biological and physicochemical properties. The high content of water in hydrogels results in enhanced biocompatibility and increased tolerance as compared to nonswelling macromolecules (8). Methylcellulose in aqueous milieu forms a semi-solid thermoreversible hydrogel. Under the influence of elevated temperature, the hydrogel converts from the sol to gel form, and inversely. The swelling capability finds the application in several industry sectors (9). The API release from the hydrogel matrix, in the case of water soluble substances, is the phenomenon of diffusion, whereas the poorly water-soluble APIs are based on the combination of the phenomenon of diffusion and erosion of the gel (10).

Validation is an action that is intended to document that an analytical method repeatedly will effect in results that fall within strictly defined acceptance criteria, which are governed by $\mathrm{ICH}$ guidelines (11). The validation of a method for content determination should be performed in line with the ICH guidelines. The specified parameters include specificity, linearity, trueness, sensitivity, precision with intermediate precision, and robustness. Validation of the analytical method in the pharmaceutical industry is one of the most important processes, leading to quality assurance of products with high risk potential. The manufactured pharmaceuticals must be inspected according to global guidelines, before the release to market circulation. The majority of issues in quality assurance results from the complexity of the hydrogel matrix (12). Standardized analytical methods for testing hydrophilic topical preparations of CD are not readily available in the literature. The aim of the study was to develop and validate an analytical method for
Table 2. System suitability data for CD.

\begin{tabular}{|c|c|}
\hline IN & $\begin{array}{c}\text { PA for } \\
\text { standard solution } \\
\text { [mAU×min] }\end{array}$ \\
\hline 1 & 11.74 \\
\hline 2 & 11.74 \\
\hline 3 & 11.69 \\
\hline 4 & 11.82 \\
\hline 5 & 11.52 \\
\hline 6 & 11.50 \\
\hline Mean & 11.67 \\
\hline RSD & 1.12 \\
\hline
\end{tabular}

CD - calcium dobesilate, IN - injection number, PA - peak area, RSD - relative standard deviation

methylcellulose hydrogel containing $\mathrm{CD}$ as an active ingredient.

\section{MATERIALS AND METHODS}

\section{Materials}

Compounds used for hydrogels preparation were described in Table 1. Calcium dobesilate $(\%$ LOD - 5.28) - FSP Galena, Wroclaw, Poland; methylcellulose - Sigma Aldrich, Poznan, Poland; cholesterol - Pharmaceutical Laboratory "Coel", Krakow, Poland, ethanol - Chempur Company, Piekary Sląskie, Poland; chloroform - Stanlab Company, Lublin, Poland were used in the study. The soy lecithin was purchased from a Polish company ECOSPA, it consists of a mixture of natural unrefined phospholipids obtained from genetically 
unrefined soybean oil (Glycine Soja). For validation of this method we used: acetonitrile (Sigma Aldrich, HPLC grade, Poznań, Poland), phosphoric acid concentrated (Sigma Aldrich, HPLC grade, Poznań, Poland) and deionized water (Hydrolab HLP20UV, Straszyn, Poland).

\section{Instrumentation}

Erweka DT 700 (Heusenstamm, Germany) dissolution tester, specialized extraction cells (Perspex, Pharma Test Apparatenbau, Hainburg, Germany), Thermo Scientific Ultimate 3000 type HPLC analyzer with Chromeleon software (Thermo Fisher Scientific, Waltham, USA), and column Standard Purospher Star 18e $250 \times 4.6$ (5 $\mu \mathrm{m})$ (Merck, Darmstadt, Germany), were used for the evaluation of the analytical method. Analytical balance AS 160/C/2 came from RADWAG (Radom, Poland), sonication bath Sonic 5 came from Polsonic Palczyński Sp.J. (Warszawa, Poland).

\section{Chromatographic conditions}

Mobile phase preparation: accurately mixed equal volumes of water and acetonitrile made up to $\mathrm{pH}$ of 2.5 with concentrated phosphoric acid, and sonicated on water bath for ten minutes. Standard stock solution preparation: the standard solution was prepared by weighing exactly $13 \mathrm{mg}$ of calcium dobesilate standard in $10.0 \mathrm{~mL}$ volumetric flask, sonicated with $5 \mathrm{ml}$ of mobile phase for $10 \mathrm{~min}$, made up to the volume of $10.0 \mathrm{~mL}$ and mixed well. Standard working solution preparation: $1.0 \mathrm{~mL}$ of above presented standard stock solution was pipetted and transferred to $10.0 \mathrm{~mL}$ volumetric flask, made up to the volume with mobile phase and mixed well. The obtained standard solution was filtered through $0.45 \mu \mathrm{m}$ nylon membrane filters directly to the HPLC vials. Received concentration of standard working solution was $0.13 \mathrm{mg} / \mathrm{mL}$, i.e. $100 \%$ target concentration.

Sample solution preparation: sample solution preparation were obtained from the dissolution studies performed via dissolution paddle method at 100 rpm. Evaluated gels were placed in the specialized extraction cells and dissolution test according to the Ph. Eur 5.0, 2.9.4 Dissolution test for transdermal patches, 2. Cell method was performed in this experiment (13). The purified water of $37^{\circ} \mathrm{C}$ as an acceptor medium, in a volume of $1000 \mathrm{~mL}$, was used during entire experiment. Samples of $2.0 \mathrm{~mL}$, initially
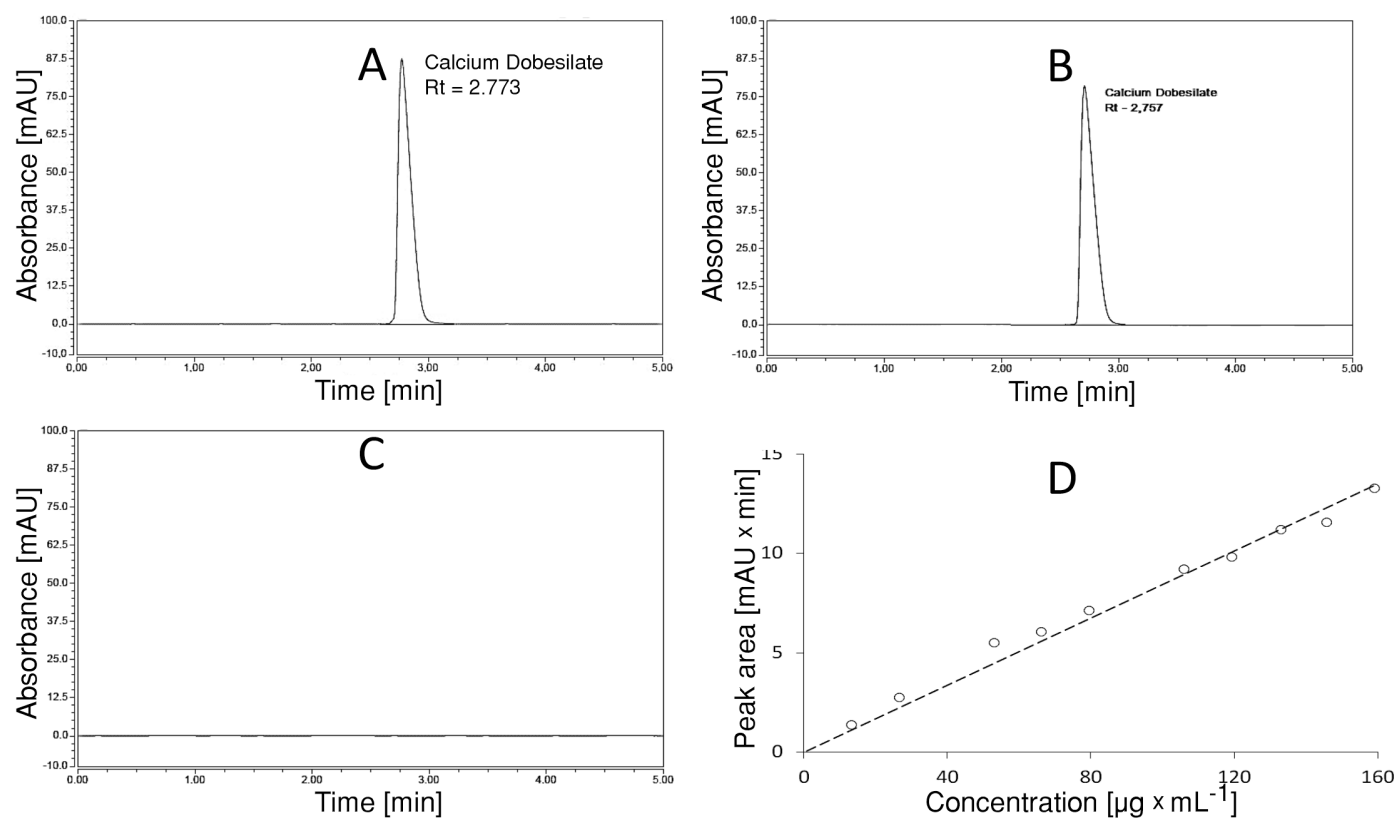

Figure 2. Exemplifications of chromatograms of standard solution (A, left), sample solution (B, right), blank solution (C, left), for the basic preparation, and calibration curve $(\mathrm{D}$, right) 
every $5 \mathrm{~min}$, then 10,15 or 20 minutes through over 270 minutes were taken and consequently filtered through RC $0.45 \mu \mathrm{m}$ syringe filters (Whatman, Little Chalfont, UK) directly to HPLC vials (VWR, Radnor, USA). The acceptor fluid was not supplemented. The plateau phase, i.e. time when $100 \%$ of calcium dobesilate was released, varied depending on the gel composition. Blank solution: as a blank solution the mobile phase was injected.

\section{RESULTS AND DISCUSSION}

\section{Method development}

The study used the methylcellulose gel due to its extensive use in the pharmaceutical, cosmetical, and biomedical industry, however, the methylcellulose analytical matrix may generate some analytical hindrances (14). Eight formulas with CD were prepared in the course of development work. However, the variability of the formulations justified eight separate validation processes, which involved tremendous analytical efforts.

To optimize the HPLC parameters several mobile phases combinations and different HPLC columns were checked. Satisfactory results were received by composing equal volumes of acetonitrile and HPLC water $50: 50(\mathrm{v} / \mathrm{v})$ with $\mathrm{pH}$ of 2.5 , using Standard Purospher Star 18e $250 \times 4.6$ (5 $\mu \mathrm{m})$ as an HPLC column. The flow rate was set at $1.00 \mathrm{~mL} / \mathrm{min}$ and column temperature at $25^{\circ} \mathrm{C}$. Injection volume was $20 \mu \mathrm{L}$ for both sample and standard solution. Various wavelengths in the range $200-400 \mathrm{~nm}$ were checked and the optimum one for detection was set at $240 \mathrm{~nm}$. The total run time of analysis was set at $5 \mathrm{~min}$ and acquired retention time was 2.7 and $3.1 \mathrm{~min}$ for calcium dobesilate depending on the hydrogel formulation; in the present study, we have obtained peak retention time comparable to the previously obtained by other researchers in the case of an ointment, which was 2.4 min (15). Respective HPLC signals reflecting calcium dobesilate content in the standard solution and in sample solution were presented in Figure 2, as well as the blank sample solution, and obtained calibration curve. It is worth to mention that the time was significantly improved compared to that of $5.83 \mathrm{~min}$ acquired for dosage forms evaluated by Tawkkoll et al. (16) and 4.34 and 8.57 min acquired in human plasma samples (17). This comparison confirms that the analysis method has been well optimized. The method was validated and checked for above - presented hydrogel formulations with calcium dobesilate, using described conditions (18).

In the case of a method developed using the HPLC apparatus, the resolution of the chromatographic system (system suitability test, SST) is usually carried out. This consists of a minimum of 6 injections of the standard solution, with $\mathrm{RSD}=2 \%$, according to ICH guidelines. SST was performed for all eight hydrogel formulations, and the SST data were presented in Table 2.

Linearity confirms that the obtained results are directly proportional to the concentration of the active substance at a given level. Linearity was determined by assessment of calcium dobesilate percentage on five various levels of concentration, i.e. $60 \%, 80 \%$, $100 \%, 120 \%$ and $140 \%$ for all evaluated hydrogels formulations. The results in the Table 3 are presented as an average of three concentrations for each sample on all levels. Results obtained for $100 \%$ concentration level were taken from the method precision results, presented in the further section.

Trueness is one of the most important parameters within the validation process and results from the comparison of respective standard and sample solutions. The exactly weighed amounts of $\mathrm{CD}$, representing 50\%, 100\%, $150 \%$ of the declared content, were added to the respective placebo formulations. At every level, we prepared three samples. Trueness

Table 3. Results of linearity evaluation for the A-H hydrogel formulations with CD.

\begin{tabular}{|c|c|c|c|c|c|c|c|c|c|}
\hline \multirow{2}{*}{$\begin{array}{c}\text { Concentration } \\
{[\%]}\end{array}$} & \multicolumn{9}{|c|}{ Formulation } \\
\cline { 2 - 9 } & $\mathrm{A}$ & $\mathrm{B}$ & $\mathrm{C}$ & $\mathrm{D}$ & $\mathrm{E}$ & $\mathrm{F}$ & $\mathrm{G}$ & $\mathrm{H}$ \\
\cline { 2 - 9 } & \multicolumn{9}{|c|}{ Recovery [\%] } \\
\hline 60 & 101.02 & 99.34 & 99.33 & 100.93 & 101.56 & 99.31 & 98.01 & 100.99 \\
\hline 80 & 100.83 & 98.95 & 99.64 & 100.87 & 101.96 & 98,31 & 98.89 & 101.93 \\
\hline 100 & 99.42 & 100.12 & 99.48 & 99.89 & 100.70 & 100.08 & 99.82 & 100.23 \\
\hline 120 & 100.12 & 100.48 & 101.31 & 101.98 & 100.33 & 101.04 & 101.51 & 101.63 \\
\hline 140 & 100.17 & 98.78 & 100.11 & 100.73 & 98.54 & 98.74 & 99.11 & 99.12 \\
\hline
\end{tabular}

CD - calcium dobesilate 
Table 4. Results of trueness evaluation for the A-H hydrogel formulations with $\mathrm{CD}$.

\begin{tabular}{|c|c|c|c|c|}
\hline Formulation & $\begin{array}{c}\mathrm{SL} \\
{[\%]}\end{array}$ & $\begin{array}{c}\text { AA } \\
{[\mathrm{mg} / 100 \mathrm{~mL}]}\end{array}$ & $\begin{array}{c}\mathrm{AR} \\
{[\mathrm{mg} / 100 \mathrm{~mL}]}\end{array}$ & $\begin{array}{l}\text { MR } \\
{[\%]}\end{array}$ \\
\hline \multirow{3}{*}{ A } & 50 & 6.63 & 6.58 & 99.36 \\
\hline & 100 & 13.25 & 13.08 & 98.74 \\
\hline & 150 & 19.88 & 19.87 & 99.96 \\
\hline \multirow{3}{*}{ B } & 50 & 6.63 & 6.66 & 100.56 \\
\hline & 100 & 13.25 & 13.17 & 99.41 \\
\hline & 150 & 19.88 & 20.08 & 101.03 \\
\hline \multirow{3}{*}{$\mathrm{C}$} & 50 & 6.63 & 6.74 & 101.74 \\
\hline & 100 & 13.25 & 13.26 & 100.05 \\
\hline & 150 & 19.88 & 20.25 & 101.86 \\
\hline \multirow{3}{*}{ D } & 50 & 6.63 & 6.65 & 100.36 \\
\hline & 100 & 13.25 & 13.05 & 98.45 \\
\hline & 150 & 19.88 & 19.63 & 98.77 \\
\hline \multirow{3}{*}{$\mathrm{E}$} & 50 & 6.63 & 6.57 & 99.21 \\
\hline & 100 & 13.25 & 13.22 & 99.78 \\
\hline & 150 & 19.88 & 20.20 & 101.63 \\
\hline \multirow{3}{*}{$\mathrm{F}$} & 50 & 6.63 & 6.72 & 101.36 \\
\hline & 100 & 13.25 & 13.38 & 100.99 \\
\hline & 150 & 19.88 & 20.17 & 101.47 \\
\hline \multirow{3}{*}{$\mathrm{G}$} & 50 & 6.625 & 6.64 & 100.28 \\
\hline & 100 & 13.25 & 13.27 & 100.12 \\
\hline & 150 & 19.88 & 19.89 & 100.09 \\
\hline \multirow{3}{*}{$\mathrm{H}$} & 50 & 6.63 & 6.53 & 98.55 \\
\hline & 100 & 13.25 & 13.03 & 98.34 \\
\hline & 150 & 19.88 & 19.63 & 98.76 \\
\hline
\end{tabular}

SL - spike level, MR - mean recovery, AA - amount added to the sample, AR - amount recorded via HPLC assessment

results are presented as a percentage in Table 4 . The accepted limits of mean recovery are between 97 and $103 \%$ according to ICH guidelines. All received results are within acceptance criteria, and the method was accurate.

A precision of the method was determined by performing the repeatability of six sample solutions prepared for evaluated hydrogel formulations. Also, the intermediate precision was assessed: respective data are attached in Table 5.

Limit of quantification (LOQ) was evaluated as the minimum level of calcium dobesilate concentration at which it could be measured with acceptable trueness and precision, and calculated according to obtained standard deviations. The LOQ was $13.25 \mu \mathrm{g} / \mathrm{mL}$ for calcium dobesilate. Robustness was evaluated in the terms of stability of samples in the fridge (over $72 \mathrm{~h}$ ), in the room temperature over $48 \mathrm{~h}$, column temperature $( \pm 5 \%)$, $\mathrm{pH}$ of mobile phase $( \pm 1 \%)$, flow rate $( \pm 5 \%)$, organic solvent excess in mobile phase $( \pm 10 \%)$, however, no significant changes were observed. The RSD in the obtained set of data did not exceed $2 \%$, and the method was considered robust to the varied environmental factors present in the course of the assay.

Validation of the above method did not result in any major difficulties, what is confirmed by respective trueness results. It is a rather rare case to produce results close to the $100 \%$ at three different levels of spiking in the analysis performed on samples from the dissolution test. Hereby obtained results are very close to the data developed in the case of an ointment with calcium dobesilate, assessed via HPLC analysis (15). However, it is worth to mention that the data were acquired from 
Table 5. Precision and intermediate precision with RSD data for evaluated formulations of calcium dobesilate: A-H.

\begin{tabular}{|c|c|c|c|c|c|c|c|c|}
\hline \multicolumn{9}{|c|}{ Recovery [\%] } \\
\hline $\mathrm{PM}$ & $\mathrm{P}$ & IP & $P$ & IP & $\mathrm{P}$ & IP & $\mathrm{P}$ & IP \\
\hline $\mathrm{SN}^{\mathrm{F}}$ & \multicolumn{2}{|c|}{ A } & \multicolumn{2}{|c|}{ B } & \multicolumn{2}{|c|}{$\mathrm{C}$} & \multicolumn{2}{|c|}{$\mathrm{D}$} \\
\hline 1 & 99.61 & 99.43 & 100.52 & 101.83 & 100.63 & 98.31 & 100.69 & 100.25 \\
\hline 2 & 101.26 & 99.09 & 100.53 & 100.73 & 100.10 & 99.31 & 99.05 & 100.09 \\
\hline 3 & 99.72 & 100.00 & 99.13 & 99.89 & 101.11 & 99.58 & 100.61 & 100.01 \\
\hline 4 & 100.06 & 99.04 & 99.70 & 99.12 & 101.90 & 100.09 & 101.53 & 99.36 \\
\hline 5 & 100.09 & 98.68 & 101.69 & 99.17 & 99.12 & 100.14 & 101.74 & 100.50 \\
\hline 6 & 100.29 & 100.31 & 101.89 & 99.97 & 100.07 & 99.44 & 100.47 & 99.15 \\
\hline M & 100.17 & 99.42 & 100.58 & 100.12 & 100.49 & 99.48 & 100.68 & 99.89 \\
\hline RSD & 0.58 & 0.69 & 1.21 & 0.66 & 1.07 & 0.38 & 1.07 & 0.55 \\
\hline $\mathrm{M}_{12}$ & \multicolumn{2}{|c|}{99.80} & \multicolumn{2}{|c|}{100.35} & \multicolumn{2}{|c|}{99.98} & \multicolumn{2}{|c|}{100.29} \\
\hline $\mathrm{RSD}_{12}$ & \multicolumn{2}{|c|}{0.70} & & & \multicolumn{2}{|c|}{0.95} & \multicolumn{2}{|c|}{0.84} \\
\hline \multicolumn{9}{|c|}{ Recovery [\%] } \\
\hline $\mathrm{PM}$ & $\mathrm{P}$ & IP & $\mathrm{P}$ & IP & $\mathrm{P}$ & IP & $\mathrm{P}$ & IP \\
\hline $\mathrm{SN}$ & \multicolumn{2}{|c|}{ E } & \multicolumn{2}{|c|}{$\mathrm{F}$} & \multicolumn{2}{|c|}{ G } & \multicolumn{2}{|c|}{$\mathrm{H}$} \\
\hline 1 & 99.80 & 101.38 & 98.84 & 99.47 & 99.20 & 99.97 & 100.58 & 98.40 \\
\hline 2 & 99.32 & 100.96 & 99.36 & 99.13 & 100.28 & 98.46 & 99.62 & 100.31 \\
\hline 3 & 101.53 & 100.94 & 101.52 & 100.95 & 101.53 & 99.25 & 100.16 & 101.13 \\
\hline 4 & 100.22 & 100.91 & 101.28 & 100.65 & 98.94 & 99.35 & 99.21 & 98.76 \\
\hline 5 & 98.41 & 99.57 & 101.21 & 100.89 & 101.34 & 100.60 & 100.21 & 101.55 \\
\hline 6 & 100.03 & 100.44 & 99.74 & 99.39 & 100.02 & 101.30 & 101.14 & 101.22 \\
\hline $\mathrm{M}$ & 99.89 & 100.70 & 100.33 & 100.08 & 100.22 & 99.82 & 100.15 & 100.23 \\
\hline RSD & 1.16 & 0.60 & 1.00 & 0.87 & 1.05 & 1.14 & 0.73 & 1.12 \\
\hline $\mathrm{M}_{12}$ & \multicolumn{2}{|c|}{100.29} & \multicolumn{2}{|c|}{100.20} & \multicolumn{2}{|c|}{100.02} & \multicolumn{2}{|c|}{100.19} \\
\hline $\mathrm{RSD}_{12}$ & \multicolumn{2}{|c|}{0.92} & \multicolumn{2}{|c|}{0.97} & \multicolumn{2}{|c|}{1.02} & \multicolumn{2}{|c|}{1.02} \\
\hline
\end{tabular}

$\mathrm{PM}$ - precision mode, $\mathrm{P}$ - precision, IP - intermediate precision, $\mathrm{SN}$ - sample number, FT - formulation type, $\mathrm{M}$ - mean, $_{12}$ - mean recovered from $\mathrm{P}$ and IP assessment, RSD - relative standard deviation, $\mathrm{RSD}_{12}$ - relative standard deviation recovered from $\mathrm{P}$ and IP assessment

quantitative content assay (15), whereas we developed a method for assessment of samples obtained in the course of the dissolution test. Obtained results are in relatively narrow limits and with definitively good precision and trueness of the analytical method. This is possibly the consequence of the physical properties of assessed formulations. Very good solubility of API in an aqueous environment, convenient preparative procedure, and perfect API dissolution are desirable, and advantageous, both for the application, as well as for the pharmaceutical availability. Additionally, the analytical procedure was readily developable and validation did not face specific hindrances, what is a huge advantage for large pharmaceutical production.

\section{CONCLUSION}

HPLC method has been developed and successfully validated for all eight hydrogel formulations as per ICH guidelines, i.e.: system suitability, linearity, trueness, precision, intermediate precision, sensitivity and robustness. All the received results were within acceptance criteria, therefore the proposed method can be used for the routine analysis of this type of CD hydrogel formulations. 


\section{REFERENCES}

1. Ciapponi A., Laffaire E., Roque M.: Angiology 55,147 (2004).

2. Flota-Cervera F., Flota-Ruiz C., Trevińo C., Berber A.: Angiology 59, 352 (2008).

3. Ribeiro M.L., Seres A.I., Carneiro A.M., Stur M., Zourdani A. et al.: Graefe's Arch. Clin. Exp. Ophthalmol. 244, 1591 (2006).

4. Ibáñez L., Ballarín E., Vidal X., Laporte J.R.: Eur. J. Clin. Pharmacol. 56, 763 (2000).

5. Wójcik - Pastuszka D., Lisik A., Twarda M., Berkowski R., Musiał W.: Curr. Issues Pharm. Med. Sci. 28, 225 (2015).

6. Lisik A., Wójcik - Pastuszka D., Twarda M., Berkowski R., Musiał W.: Curr. Issues Pharm. Med. Sci. 28, 136 (2015).

7. Hamidi M., Azadi A., Rafiei P.: Adv. Drug Deliv. Rev. 60, 1638 (2008).

8. Kanjickal D., Lopina S., Evancho-Chapman M.M., Schmidt S., Donovan D.: Mater. Res. Part A. 74, 454 (2005).

9. Nishinari K., Hofmann K.E., Moritaka H., Kohyama K., Nishinari N.: Macromol. Chem. Phys. 198, 1217 (1997).

10. Mitchell K., Ford J.L., Armstrong D.J., Elliott P.N.C., Hogan J.E., Rostron C.: Int. J. Pharm. vol. 100, 165 (1993).
11. International Conference on Harmonisation of Technical Requirements for Registration of Pharmaceuticals for Human use: Validation of Analytical Procedures: Text and Methodology Q2(R1); Current Step 4 version Parent Guideline dated 27 October 1994 (Complementary Guideline on Methodology dated 6 November 1996 incorporated in November 2005).

12. Omidian H., Park K.: J. Drug Del. Sci. Tech. 18. 83 (2008).

13. European Pharmacopeia 5.0, 2.9.4 Dissolution test for transdermal patches. 2. Cell Method. 01/2005:20904.

14. Turowski M., Deshmukh B., Harfmann R., Conklin J., Lynch S.: J. Food Compos Anal. 20. 420 (2007).

15. Zivanovic Lj., Zecevic M., Markovic S., Petrovic S., Ivanovic I.: J. Chromatogr A. 1088. 182 (2005).

16. Tawakkol S.M., Fahmy N.M., Lotfy H.M., ElAtty Shehata M.A.: Int. J. Pharm. Pharm. Sci. 6. 123 (2014).

17. Róna K., Ary K.: J. Chromatogr. B Biomed. Sci. Appl. 755, 245 (2005).

18. Moldoveanu S.C., David V.: Chapter 1 - Start of the Implementation of a New HPLC Method. Selection of the HPLC Method in Chemical Analysis. pp. 1-29. ISBN: 978-0-12-803684-6. 2017.

Received: 28.07 .2017 